\title{
Increased capacity with world-class piston diaphragm pumping technology
}

\author{
J. Kuenen GEHO Pumps, Weir Minerals Netherlands b.v., the Netherlands
}

\begin{abstract}
High density pumping of the abrasive slurry by piston diaphragm pumps has been selected as the most economical option for high pumping capacities for large process feed installations or large mine tailings transport systems.

The GEHO development of the patented GLORES system (Geho LOad REduction System) increased possible power rating of the triplex piston diaphragm pump to 2,800 $\mathrm{kW}$. For a multi-pump station, this enables a pump station design with an acceptable, lower number of pumps. The development of the largest pump diaphragm in the world and the use of numerical tools for the analysis of dynamic phenomena within the pump, enables a reliable pump design for the increased flow rate from a hydraulic perspective as well.

This paper describes the main development activities mentioned and focuses on the description of the GLORES system and the use of numerical tools for the analysis of the law of scale for dynamic phenomena which become more important to consider with increasing pump size. The GLORES system is a load balancing system for single acting piston diaphragm pumps which significantly increases the rod load rating of a specific power end. This significantly increases the maximum hydraulic power that can be generated by a single pump, enabling a more economical design of high volume positive displacement (PD) pump stations. GLORES in combination with the developments in the analysis of pump dynamics enables the design of slurry and tailings transport systems based on GEHO piston diaphragm pump technology with transport requirements of 10-100 Mtpa of dry solids.
\end{abstract}

\section{Introduction}

The first GEHO piston diaphragm pump was developed in the early 1970s for filter press feeding of abrasive iron oxide scales in the German steel industry. The GEHO piston diaphragm pump distinguished itself from other available piston diaphragm pump types by an optimal shaped, moulded diaphragm and a contact free electro-hydraulic leakage control system which have later shown to be the key to the development of large reliable piston diaphragm pumps for slurry transportation. In the late 1970s, the pump size was expanded for the application in bauxite digester feeding, iron ore transport and red mud tailings disposal (Stephan and Navrade, 1984). In the 1980s the technology was promoted further (Holthuis and Simons, 1980, 1981; Simons, 1987) and slowly gained acceptance in the hydro transport community (Gandhi et al., 1980; Venton and Cowper, 1986; Lush and Pope, 1987) before becoming a popular PD slurry pump technology in the 1990s (van Rijswick, 1991) and into the 21st century (Gandhi et al., 2008; Kuenen, 2008). The technology has now matured into the industry standard pump technology for high pressure slurry pumping, backed up by the many references world wide. During the last four decades the hydraulic power steadily increased as can be seen in Figure 1. 


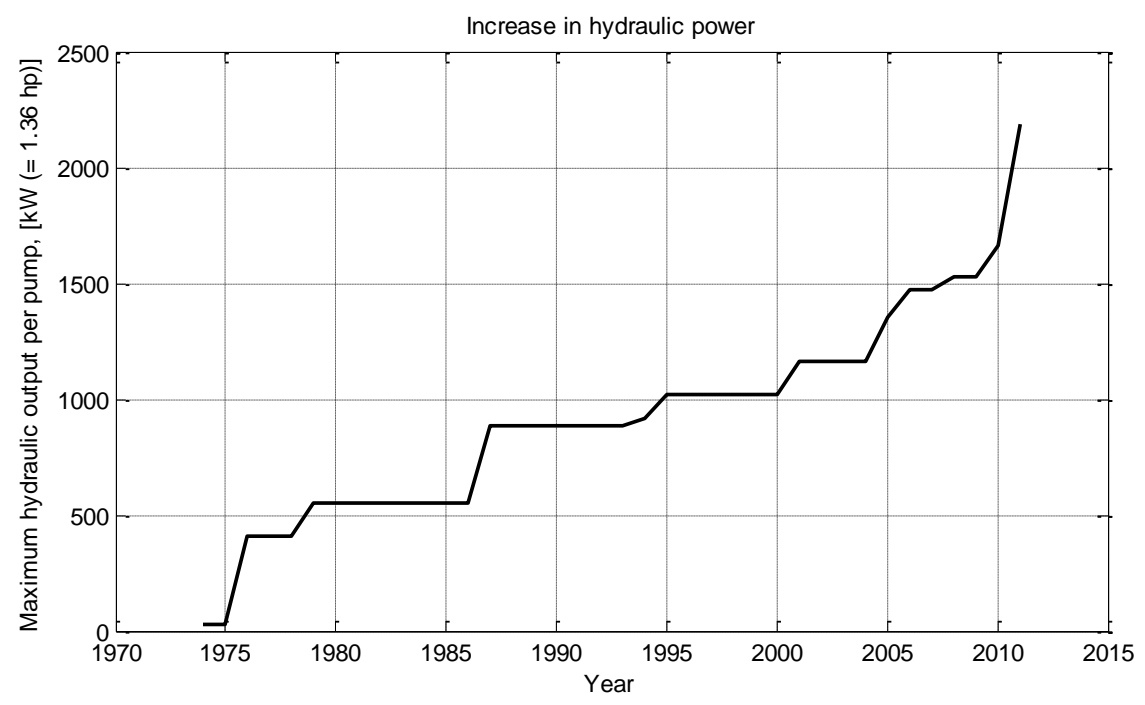

Figure 1 Increase in hydraulic power of GEHO PD pump

Next to the increase in flow rate and hydraulic output per pump, the size of the transport systems in which piston diaphragm pumps are used increased as well in recent years; MBP bauxite concentrate pipeline 2006/2010: 9/13.5 Mtpa (Gandhi et al., 2008), Anglo Ferrous Minas-Rio iron ore concentrate pipeline: 26.5 Mtpa, Toromocho copper tailings pipeline: $51 \mathrm{Mtpa}$. Only recently, the use of high density tailing disposal of high volume tailings larger than $100 \mathrm{ktpd}$, as are present in the copper and oil sand industry, were considered a future challenge (Rayo et al., 2009). Only few systems larger than $10 \mathrm{ktpd}$ are present and non larger than $50 \mathrm{ktpd}$ (Rayo et al., 2009). In (Rayo et al., 2009) a study is presented for a large copper tailing disposal system in which 20-25, 1,300 kW, PD pumps are used, assuming this to be the largest available PD slurry pump size. With the development of GLORES, the required number of pumps can be more than halved, further increasing the feasibility of such applications. The increase in pump capacity was possible by the combination of GLORES, combined with continuously incorporating the field experiences of the operational pumps in newer designs, conservative design and selection guidelines and in depth research and development using numerical modelling techniques, combined with experimental research for verification.

\section{Piston diaphragm pump design and selection}

Many design and selection choices have to be made, starting from the initial project requirements, which are defined by the amount of dry solids or volumes to be transported. In order to specify the flow rate and pressure requirements for the pumping system, the solids concentration and slurry rheology have to be determined also. The use of PD slurry pumps enables pumping of slurries with high solids concentration and viscosities which requires higher discharge pressures, but lower flow rates for a given transport problem. From a total cost of ownership perspective, GEHO piston diaphragm pump are preferred as these pumps have very high efficiencies and a low number of wear parts, resulting in low operating cost compared to other PD pump technologies (Holthuis and Simons, 1980, 1981; Kuenen, 2008; Simons, 1987; van Rijswick, 1991). Nowadays for red mud or other high density mine tailings disposal systems, the GEHO PD pump technology enabled a tailing transport in near paste conditions which enables a dry stacking type of tailing disposal (Kuenen, 2008). Pumping tailings at proper consistency ensures optimal spreading at the disposal area with a small angle of repose and very smooth surface. This pumping is preferred against mechanical spreading because of the smooth surface rainwater can run off at low velocity and no erosion gullies are created. For wet climate conditions this is another reason to go for high concentrated disposal by pumping (Kuenen, 2008) instead of trucking.

Critical evaluation of different pump technologies is crucial for the design of an optimal slurry transport system. The selection of different pump technologies results in quite different possibilities regarding solids concentration, rheology, flow rate and discharge pressure for a given transport problem. 


\subsection{Duplex double acting and triplex single acting piston diaphragm pumps}

Before indicating the design and selection variables for the piston diaphragm pump, its operation is explained first.
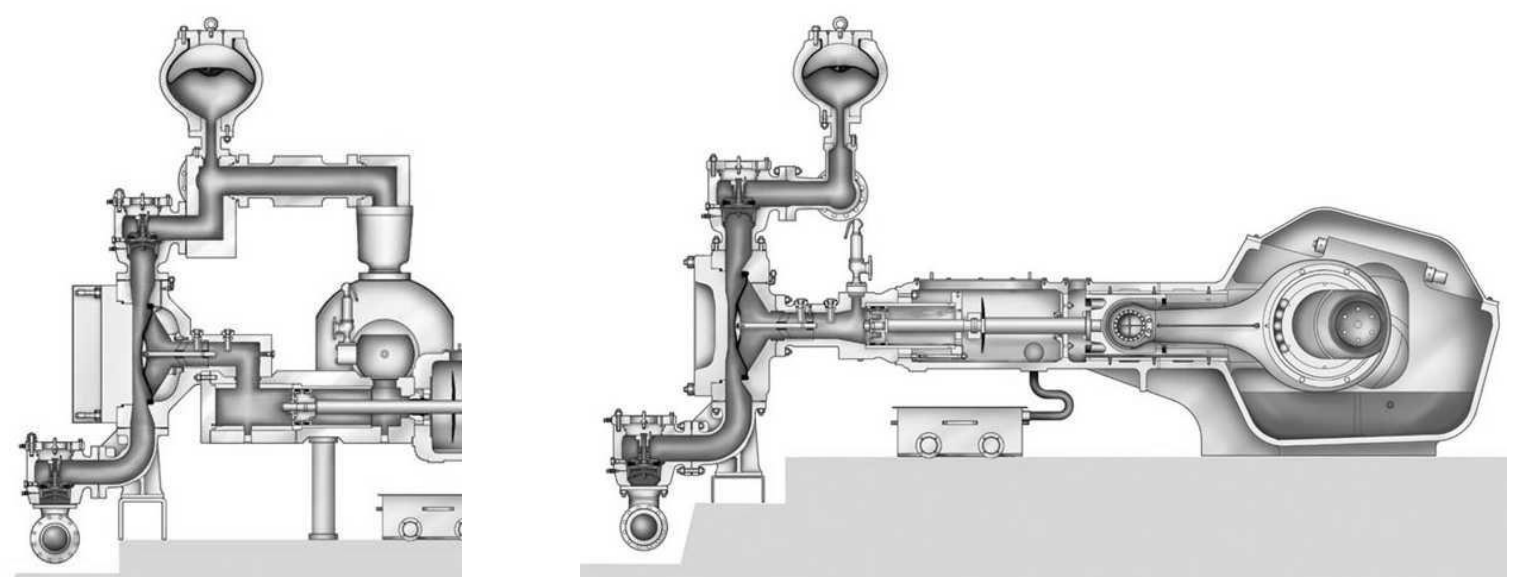

Figure 2 Cross section of a GEHO double (left) and single (right) acting piston diaphragm pump

In Figure 2 a crank mechanism is shown which generates a reciprocating motion of the piston via the piston rod in which the so-called rod load, $F_{\text {rod }}$, is present. This piston displaces a hydraulic fluid, called the propelling liquid, which displaces a rubber diaphragm in the pump chamber. When combined with self acting non-return valves in the suction and discharge manifold, a positive displacement pump action is generated. As the flow is generated by a more or less sinusoidal motion of the piston, a flow pulsation is present which is damped by a volume absorbing device such as a gas filled accumulator. The main benefit of the piston diaphragm pump for slurry applications is the reduced number of wear parts compared to other PD pump technologies such a piston and plunger pumps. In double acting pumps the piston is displacing fluid on both sides and is driving two pump chambers. This almost doubles the flow rate per piston when compared to a single acting pump in which the piston is only displacing fluid on one side of the piston.

Next to the single or double acting nature, a variation in the number of pistons is possible. The nomenclature from the Hydraulic Institute (ANSI/HI 6.1-6.5-1994, 1994) for reciprocating pumps is also used for the identification of piston diaphragm; the first part of the name identifies the number of cylinders, or subsequently; simplex, duplex, triplex, quadruplex, quintuplex, etc., followed by the single or double acting nature of the piston. In the GEHO piston diaphragm pump line, two types dominate; the triplex single acting and the duplex double acting piston diaphragm pump.

\subsection{PD pump design and selection variables}

In order to evaluate different pump designs it is important to understand the PD pumps design and selection process. The PD pump design and selection is characterised by a relatively large number of design and selection variables. The relationship between the most important PD pump design and selection variables is given by Equation (1). The quantity between the equality signs equals the hydraulic power of a single pump, but is expressed in different design and selection variables each time in order to show the relationship between them. The upper line shows high level project specific variables and the lower line shows more low level pump design and selection specific variables which can be expressed in liquid end or power end specific variables. Equation (1) is further considered self explanatory. 


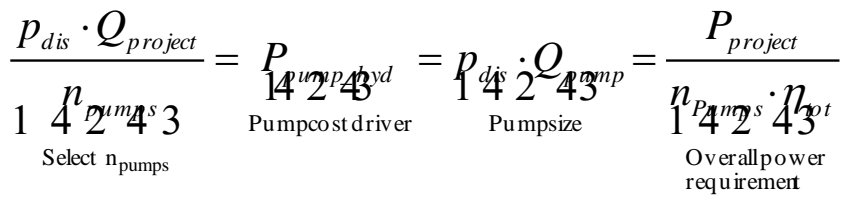

$$
\begin{aligned}
& =p_{d i s} \cdot \eta_{v o l} \cdot \frac{n_{\text {cham }} \cdot V_{\text {stroke }} \cdot s p m}{1 \underset{\text { Liquid end selection }}{42_{443}}}=\eta_{\text {vol }} \cdot \frac{n_{\text {cyl }} \cdot n_{\text {cham_per_cyl }} \cdot F_{\text {rod }} \cdot S \cdot s p m}{1444 \underset{\text { Powerend selection }}{420444434}}
\end{aligned}
$$

Where:

$\begin{array}{rll}p & = & \text { pressure }(\mathrm{Pa}) . \\ Q & = & \text { flow }\left(\mathrm{m}^{3} / \mathrm{h}\right) . \\ n & = & \text { number. } \\ P & = & \text { power }(\mathrm{W}) . \\ \eta & = & \text { efficiency. } \\ V & = & \text { volume }\left(\mathrm{m}^{3}\right) . \\ s p m & = & \text { pump stroke rate }\left(\mathrm{min}^{-1}\right) \\ F & = & \text { force }(\mathrm{N}) . \\ S & = & \text { stroke length }(\mathrm{m}) .\end{array}$

The selection of these variables is a result of a reliability and economic evaluation. For the reliability evaluation two general rules hold:

1. Parts that are arranged in series from a reliability perspective reduce the system reliability and should be minimised as far as possible. For example all parts in a single pump whose failure requires the shutdown of the pump are arranged in series from the reliability perspective of the pump.

2. Parts that are arranged in parallel from a reliability perspective increase the reliability when they are redundant. For example the use of several PD pumps in parallel increases the reliability of the total system as the failure of one pump doesn't have to result in the failure of the entire system. The level of redundancy is a function of the number of parallel pumps and the installed stand-by capacity with respect to maximum, nominal and minimum flow requirements.

The economic evaluation should be based on both capital costs and on operational costs which include maintenance costs, wear parts costs and energy costs. In the economic evaluation, the economic law of scale is important to consider which generally states that the use of fewer larger components or machines is more cost effective than the use of smaller components or machines. The law of scale holds both in the evaluation of the capital costs but also in the evaluation of operating costs, as the maintenance of fewer parts is more cost effective. In order to apply the reliability and economic evaluation to the design of a PD pump station, Equation (1) can be used. With reference to Equation (1), the two reliability rules and the economic law of scale the following general guidelines can be derived:

- The economic law of scale dictates the use of a small number of large size pumps while reliability might require a larger number of parallel pumps in a pump station, including stand-by capacity. The optimum number of pumps is therefore the minimum number of pumps which still fulfils the reliability requirements. The minimum number of pumps is also limited by the maximum size of pumps available.

- From a cost perspective, the number of parallel components within a pump should be as small as possible; one big pump chamber per pump is more cost effective than two smaller pump chambers per pump. This holds for both the number of parallel pump chambers as well as for the number of parallel cylinders. 
- From a reliability perspective the number of parallel components should be as small as possible as the components within a single pump are arranged in series from a reliability perspective. This especially holds for the number of pump chambers in PD slurry pumps as the number of wear parts is proportional with the number of pump chambers. This is less important for the number of parallel cylinders as the mean time to failure of the power end components is much larger than the mean time to failure of the wear parts in the pump chamber such as the self acting valves.

Equation (1) further indicates the economic benefit of higher stroke rates. In practice the maximum stroke rate is limited by reliability requirements as the stroke rate influences the wear life of the valves. In larger size piston diaphragm pumps the stroke rate is further more limited by dynamic effects of scale which are further described in Section 4.

\subsection{Triplex single acting versus duplex double acting piston diaphragm pumps}

In Section 2.1 both the triplex SA as well as the duplex DA pumps have been described. Using the guidelines for the PD pump selection based on Equation (1), the application of the reliability rules and the economic law of scale, a clear comparison between the triplex SA and duplex DA piston diaphragm pumps can be made. The main advantages of the duplex DA over the triplex SA piston diaphragm pump can be summarised as follows:

- More cost effective power end design because of the two cylinder DA design versus three cylinder SA design.

- Higher available pump power for a given maximum rod load and stroke length.

- Unloading of the power end by higher suction pressures (suction pressure on one piston side decreases the rod load generated by the discharge pressure on the other side of the piston, see Figure 2).

- Higher available pump flow for a given maximum pump chamber volume.

The advantages of the triplex SA over the duplex DA piston diaphragm pump can be summarised as follows:

- Lower flow pulsations, approximately a factor two. This is a specific consequence of the single versus double acting operating principle (van Rijswick, 2007). A triplex single acting PD pump therefore requires a much lower dampening volume, approximately a factor 5 , and therefore generally has lower pressure pulsations.

- Lower number of pump chambers, three for triplex SA versus four for duplex DA:

- The smaller number of larger size pump chambers results in a more cost effective liquid end, especially in case of special material requirements.

- The lower number of wear parts results in a higher pump reliability as the probability of failure is reduced, which is especially important in abrasive slurry pumping.

- The lower number of wear parts results in lower maintenance costs.

- Lower torque fluctuation. Similar to the flow pulsation, the torque fluctuation of the triplex SA pumps is approximately 50\% of that of a duplex DA pump. This lowers the requirements for the pump drive, especially for the gear box and frequency converter.

- Lower mechanical unbalances. As the three crank journals of a triplex single acting PD pump are uniformly phased at $120^{\circ}$, compared to the two non-uniformly $90^{\circ}$ phased crank journals of the duplex double acting PD pump, much lower mechanical unbalances result. For small size, and low speed pumps these unbalanced loads can be neglected compared to the weight of the pump but for the larger and higher stroke rate pumps these unbalanced loads should be included in the foundation design. 


\section{GLORES}

As described in the previous section the triplex SA piston diaphragm pump is preferred above the duplex DA piston diaphragm pump from a liquid end and dynamic perspective. The duplex DA piston diaphragm pump however, is more cost effective from a power end perspective and allows the selection of a higher power and/or flow rate per pump for a given maximum rod load and pump chamber volume respectively. In order to combine the benefits of the duplex DA and triplex SA piston diaphragm pump, WEIR Minerals Netherlands has developed and patented a load reduction system called GLORES for single acting piston diaphragm pumps. GLORES greatly reduces the load on the pump power end thereby increasing the power rating of a specific power end. This enables the selection of a more cost effective single acting power end for a given application or a lower number of higher power pumps for high power applications.

The pump chamber pressure variation in time can be approximated by a square wave; during the suction stroke the pressure is equal to the suction pressure and during the discharge stroke it is equal to the discharge pressure. This pump chamber pressure is transferred into the rod load via the surface area of the piston, which therefore can be approximated by a square wave as well, as shown in Figure 4 by $F_{\text {piston. }}$ The rod load generated by the discharge pressure is high during the discharge stroke of a single acting PD pump, but low during the suction stroke as the suction pressure is normally negligibly small compared to the discharge pressure. The power end components in a single acting PD pump are therefore only loaded during 50\% of the crankshaft revolution.

The concept of GLORES is based on storing energy during the suction stroke by additionally loading the piston in opposite direction which is subsequently used to assist the piston in the discharge stroke. This concept is best explained by Figure 3a, in which a piston is shown which is loaded by a mechanical spring on the back side of the piston. During the suction stroke of the piston shown in Figure 3a, energy is stored in the spring which is released during the discharge stroke. The spring load increases the piston rod load during the suction stroke, in opposite direction of the pressure load in the pump chamber, but lowers the piston rod load during the discharge stroke. Although this spring analogy works well for explaining the basic concept of GLORES, it is not considered to be a practical solution for rod load balancing. GLORES therefore uses a hydraulic system for load balancing. The backside of the piston is loaded by a constant hydraulic pressure instead of a spring load. In a simplex power end, a large volume absorbing device would be required in order to absorb the swept volume of the piston while maintaining a constant pressure. In a multi cylinder pump it is possible however to connect the backsides of the individual cylinders allowing the hydraulic fluid to flow from one cylinder to the other during the crankshaft revolution as is shown in Figure 3.
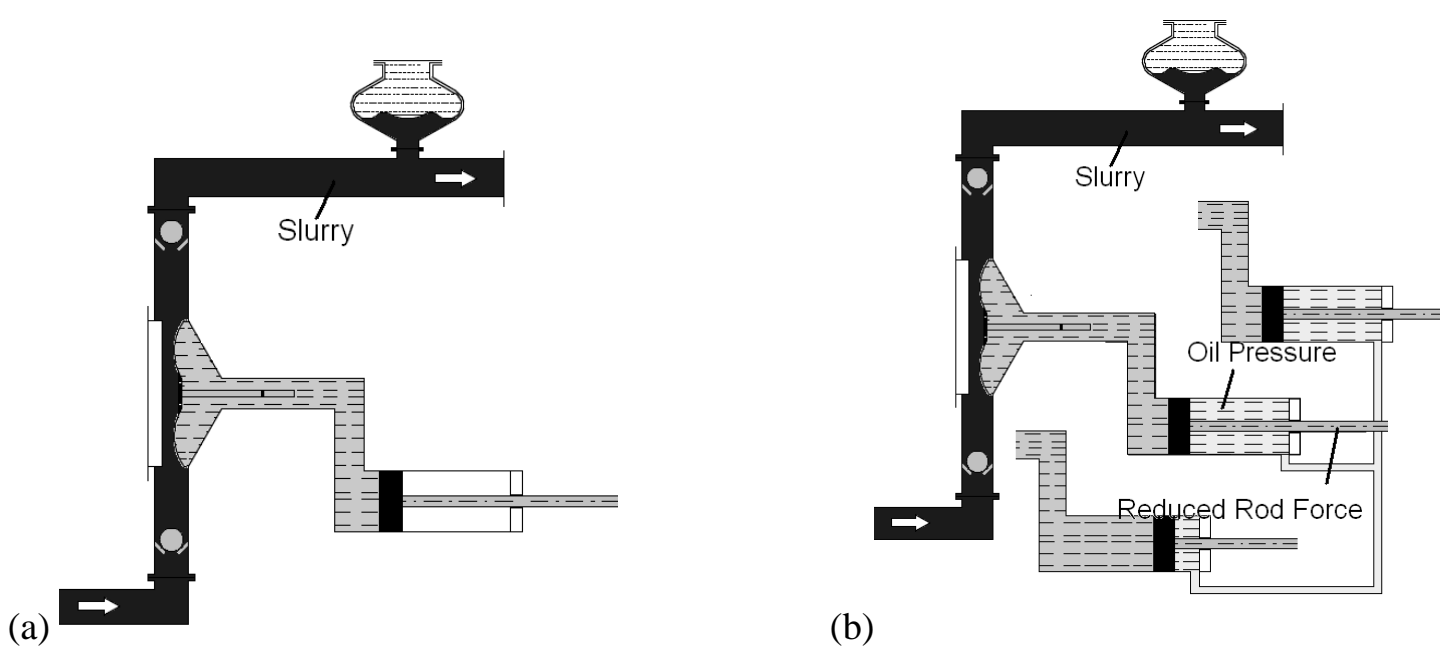

(b)

\section{Figure 3 GLORES concept: (a) Spring analogy, (b) Triplex SA with hydraulic load balancing}

When the piston phasing is uniformly distributed across the crankshaft revolution the theoretical volume fluctuation in the balancing circuit is zero. This allows the design of a very compact hydraulic balancing circuit without the need for large volume absorbing devices. The effect on the piston rod load is shown in Figure 4. 


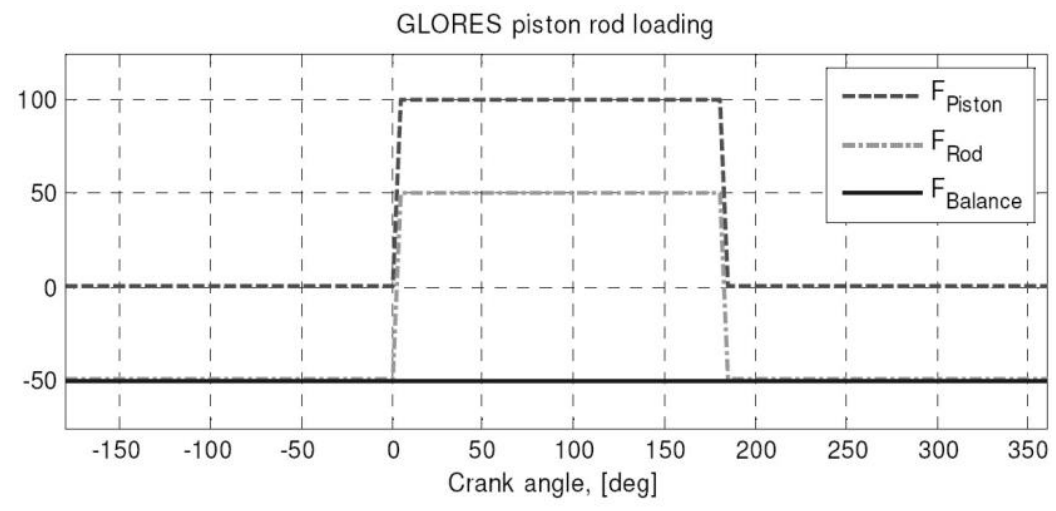

\section{Figure 4 Rod load with and without GLORES}

The rod load shown in Figure 4 is normalised to the maximum hydraulic load on the piston generated by pump chamber pressure. For simplicity, the chamber pressure during the suction stoke is assumed to be zero. In the single acting piston diaphragm pump without GLORES, the rod load is equal to the piston load, $F_{\text {Piston, }}$, which is fluctuating between 0 and $100 \%$. When GLORES is enabled, a hydraulic pressure is applied to the backside of the piston which generates the balancing load, $F_{\text {Balance, }}$ which is the average of the rod load during the suction and discharge stroke, in this case $50 \%$. The result is that the rod load seen by the power end, $F_{\text {rod }}$, changes from a 0 to plus $100 \%$ fluctuation to a minus $50 \%$ to plus $50 \%$ fluctuation. The amplitude of the rod load is not changed but the maximum load level has been reduced by a factor 2 .

When GLORES is enabled, both tension and compression rod loads are present at the same time in different piston rod which has a very beneficial effect on the bending moment of the crankshaft, which is reduced approximately a factor 3 as can be seen in Figure 5. This has a very beneficial effect on the crankshaft bending stress and deflection, eliminating any requirement for intermediate bearings. The driving torque and its fluctuation in time remain unaffected by GLORES as the GLORES balancing loads, $F_{\text {Balance }}$, requires no driving torque as they are balanced within the power end by the uniform piston phasing.

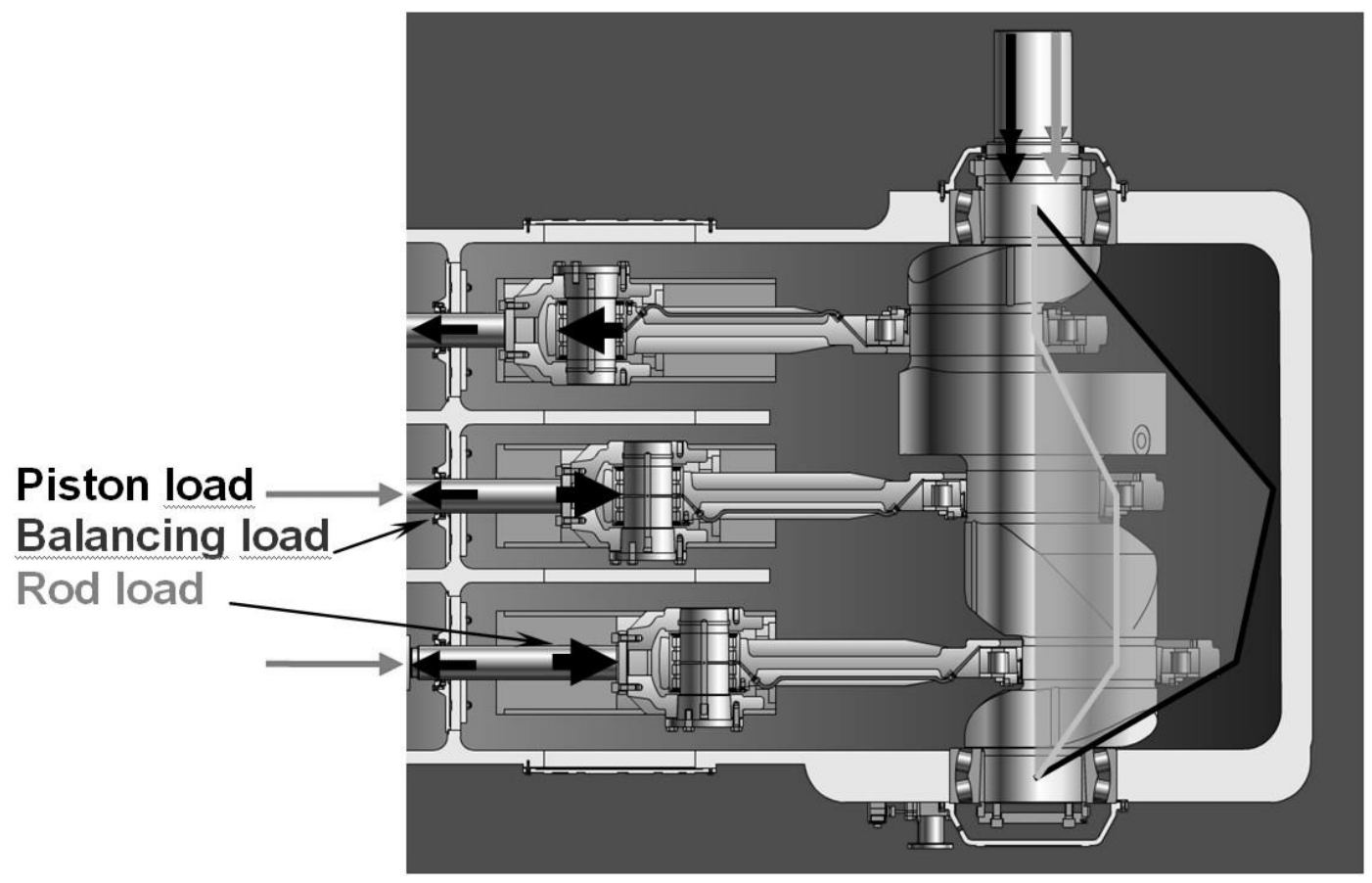

Figure 5 Bending moment on triplex SA crankshaft with and without GLORES 
The roller bearing loads are reduced by a factor 2 as well, but the duty cycle of this load changes from $50-100 \%$. The effect on bearing life can be evaluated using the equivalent load calculation according (ISO $281: 2007,2007)$ shown in Equation (2).

$$
F_{e q}=\sqrt[c]{\frac{T_{s u c} \cdot F_{s u c}^{c}+T_{d i s} \cdot F_{d i s}^{c}}{T_{s u c}+T_{d i s}}} \Rightarrow L_{10 h}=\frac{10^{6}}{60 \cdot r p m} \cdot\left(\frac{C_{d y n}}{F_{e q}}\right)^{c}
$$

Where:

$\begin{array}{lll}T & = & \text { time period }(\mathrm{s}) . \\ c & = & \text { load exponent. } \\ L_{10 h} & = & \text { nominal bearing life }(\mathrm{h}) . \\ C_{d y n} & = & \text { dynamic load rating }(\mathrm{N}) .\end{array}$

With a load exponent $c=10 / 3$, this gives a reduction of the equivalent bearing load of a factor 1.6 , or when expressed in bearing life, an increase bearing life of a factor 5.

The GLORES system is particularly suited for piston diaphragm pumps as it uses the already available propelling liquid for the load balancing. The pressure control of the GLORES system is integrated within the existing pump controller. The required GLORES pressure is based on the actual suction and discharge pressure.

The development project within Weir Minerals Netherlands involved the construction of a full scale prototype pump which has been subjected to several hundred hours of testing at the factory test stand for evaluation of the GLORES performance and fine tuning of the system. This testing included strain gauge measurements on the piston rod. The results of some stain gauge measurements are shown in Figure 6 where one can see that the piston load is fluctuating between approximately $0 \mathrm{kN}$ and $710 \mathrm{kN}$ as calculated from the pump chamber pressure measurement. The balancing load is a more or less constant load at approximately $355 \mathrm{kN}$, calculated from the GLORES balancing pressure measurement. The resulting rod load is initially fluctuating between $-355 \mathrm{kN}$ and $+355 \mathrm{kN}$ as calculated from the stain gauge measurement. After approximately 10 seconds the GLORES pressure control is deliberately disabled in order to show the rod load approaching the piston load. At approximately 35 seconds the GLORES pressure control is enabled again showing the increase in balancing load which balances the rod load again around a zero mean value.

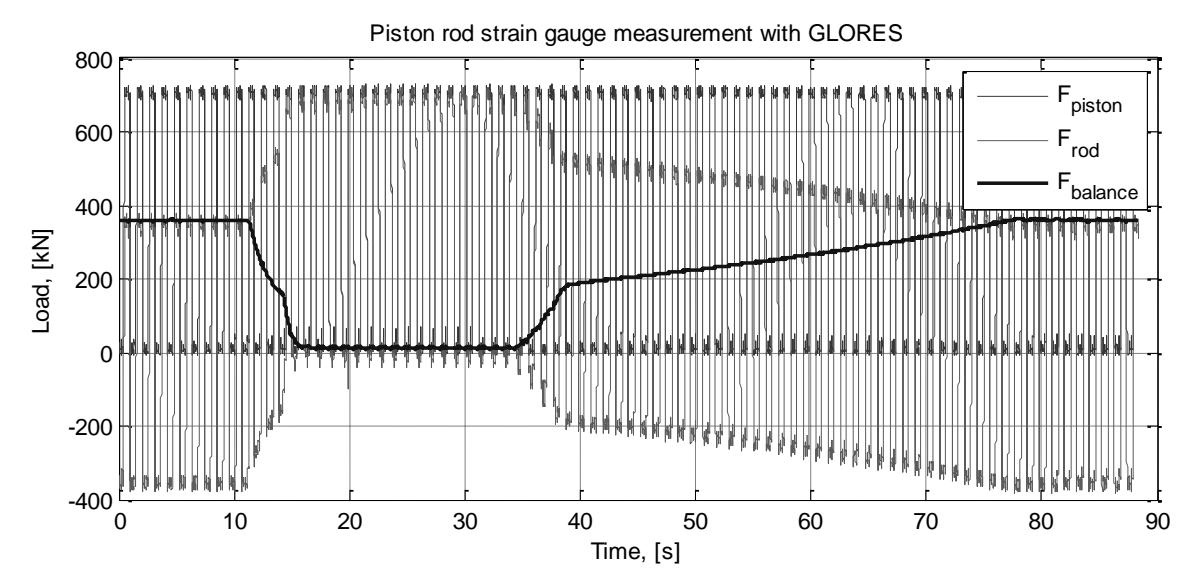

Figure 6 Strain gauge measurements on piston rod of GEHO pump with GLORES

Some components also required a re-design in order to make them suitable for the bi-directional loading condition. The re-design for the bi-directional loading is based on the design rules which are proven in the double acting pumps, in which the rod load is of bi-directional nature as well.

When going back to the advantages of the duplex DA and triplex SA piston diaphragm pumps, one can see that all the advantages of the triplex pump are maintained, while the first three advantages of the duplex 
pump are superseded; a triplex SA power end with GLORES is more cost effective than a duplex DA power end and the available power for a given maximum rod load is higher a well. The unloading of the power end in case of higher suction pressures can be obtained using GLORES when the balancing load is the average of suction and discharge load on the piston. The theoretically higher flow rate capacity of a duplex DA piston diaphragm pump for a given maximum pump chamber size remains. However in the next section it will be shown that, especially for high volume applications, the triplex SA piston diaphragm pump is preferred above the duplex DA piston diaphragm pump.

\section{$4 \quad$ Scaling laws in pump dynamics}

As described in Section 3, GLORES significantly increases the power rating of single acting power ends. This enables the design and selection of piston diaphragm pumps with much higher flow rates than before. This requires increasing the liquid end modules as well. This increase however, is not just simply increasing the size of these modules. While increasing the size of these liquid end modules, several dynamic aspects become important to consider in the design and selection of the piston diaphragm pump which are less important in smaller pumps. This is a result of the laws of scale that hold for the diverse dynamic aspects which can be grouped as follows:

1. Valve dynamics: the motion of the valves is driven by the force balance on the valve body which incorporates valve inertia, valve weight, spring load, valve pressure drop and valve drag. The portion of the valve drag in the force balance increases for increasing valve size which can result in large valve closing delays when not properly predicted and compensated by the spring load. The spring load, however, is a balance between valve closing delay and valve opening. The valve opening influences the maximum particle size which can pass but also the flow velocities in the valve gap, the latter being important for the erosion wear of the valve housings. Weir Minerals Netherlands has developed numerical models in order to predict the dynamic behaviour of the valves. These models are used for proper selection of valve sizes and spring loads depending on the operating parameters, including slurry properties such as density and viscosity.

2. Pressure dynamics: the increased importance for proper pressure pulsation control for larger systems is explained in Section 4.1.

3. Diaphragm deformation: the diaphragm deformation is caused by fluid forces acting on the diaphragm which are not always symmetric. In small piston diaphragm pumps the asymmetric fluid forces can be neglected and only a symmetrical volumetric displacement of the diaphragm is present. In larger piston diaphragm pumps, however, the asymmetrical diaphragm deformation has to be included in the design and selection of the pump. Asymmetric fluid forces on the diaphragm are for example created by convective acceleration pressures by the non uniform flow in the diaphragm housing and hydrostatic pressure imbalances across the diaphragm, created by the density differences between the slurry and the propelling liquid. These asymmetric fluid forces generate increased strain levels in the diaphragm material. As the diaphragm is flexed every stroke of the pump, approximately $30 \times 10^{6}$ times a year in a continuous $8,000 \mathrm{~h} /$ year service, early diaphragm fatigue failures can result when the strain levels are not kept below some limit. Incorrect prediction of these asymmetric forces and resulting strain levels can be the difference between a GEHO diaphragm life of 8,000-20,000 hours or only a few hundred hours. If diaphragm life is only a few hundred hours, a double or even triple diaphragm design will not improve the situation. Premature failure should be avoided by design instead of trying to compensate by a second or third diaphragm. Weir Minerals Netherlands uses diaphragm selection guidelines which are based on detailed analysis of the strain levels in the GEHO diaphragm with non-linear finite element models which are combined with almost 40 years of operational experience with GEHO PD pumps in slurry applications.

All these aspects incorporate specific laws of scale which have to be included for a reliable pump design. It is beyond the scope of this paper to describe all the laws of scale in detail. In Section 4.1 some details and some results of numerical models regarding pressure dynamics will be given. All the models have been verified experimentally, some of this verification is described in van Rijswick (2007). 


\subsection{Pressure dynamics}

The increased pump capacity, which is enabled by GLORES, requires additional focus on pressure dynamics. Crankshaft driven PD pumps inherently generate a non-constant flow. In order to attenuate this flow pulsation, volume absorbing devices or pulsation dampeners are generally used on these pumps. As already mentioned in Section 2.3 triplex SA positive displacement pumps generate much lower flow pulsations than duplex DA positive displacement pumps. For an equal pressure pulsation level a duplex DA pump requires approximately five times more dampening volume. This is not always feasible; hence duplex DA pumps generally tend to have higher pressure pulsation levels than triplex SA pumps. For higher flow rates, triplex SA piston diaphragm pumps equipped with GLORES are therefore preferred above duplex DA piston diaphragm pumps.

Appropriate pressure pulsation control is more important for high volume applications, as the pressure pulsations create unbalanced loads in the piping which are proportional with pipe cross sectional area (van Rijswick, 2007). The unbalanced loads can result in pipe vibration when the piping is not properly supported. In small systems appropriate pipe support is not an issue and in case of high vibration levels it is relatively easy to add additional supports. In high volume applications with large pipe diameters the unbalanced loads can be of considerable magnitude such that appropriate pipe support is no longer feasible or requires expensive supports with massive foundations when the pressure pulsations are not sufficiently controlled.

Conventional dampener selection methods assume full absorption of the flow pulsation by adiabatic compression and expansion of the gas in the dampener. This approach however neglects the presence of high frequency pressure pulsations and resonances in the system connected to a single pump (van Rijswick, 2007). In smaller low speed piston diaphragm pumps, these high frequency pressure pulsations are small compared to the low frequency pulsation, which are appropriately damped by the dampener. In larger piston diaphragm pumps however, these high frequency pressure pulsation can no longer be neglected and appropriate measures should be taken. In Figure 7 the results of a simulation of high frequency pressure pulsations is shown for a large triplex SA piston diaphragm pump. The difference is shown between a pump equipped with a standard, on the market available, dampener, selected according the conventional methods, versus a pump equipped with an optimised dampening system in which the fluid passages and number and location of dampeners on the pump have been optimised. In Figure 7 one can see that the low frequency pulsation is equal for both cases as this is dependent on the gas volume, which is equal in both cases. However, the high frequency pulsation is reduced by a factor 2.5 by the optimised dampening. The significant reduction of high frequency pressure pulsations is important for limiting the vibration level of the pump, but more important the vibration level of the attached piping, in which the pressure pulsations generate unbalanced mechanical loads.

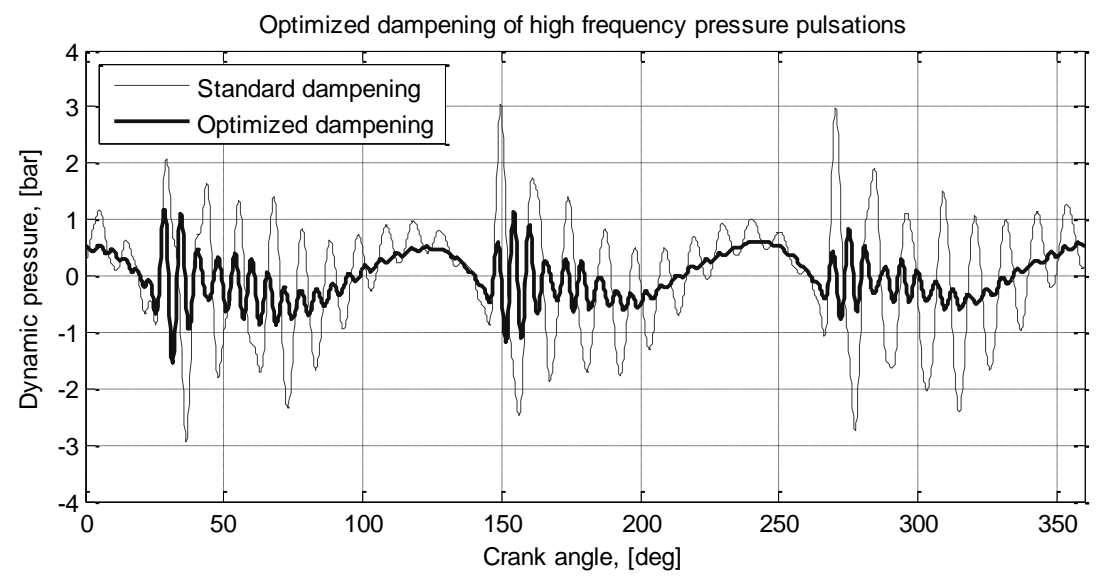

Figure 7 Optimised attenuation of high frequency pressure pulsations

Next to the high frequency pulsations, interaction resonances are of concern in high volume piston diaphragm pump stations. Interaction resonances are the result of the excitation of hydraulic resonances modes in a multi PD pump station by the individual pumps in the pump station (van Rijswick, 2007). Next to the increase of pump size, the number of pumps increases for the largest volume PD pump stations as the 
maximum available pump size is limiting. With the increasing number of pumps in a PD pump station, the susceptibility for the excitation of the interaction resonances also increases. In order to exclude the excitation of these interaction resonances, Weir Minerals Netherlands has developed a method for synchronisation of the individual PD pumps in a PD pump station. A synchronisation controller then synchronises the crankshafts of the individual pumps at a pre-determined phase shift in order to exclude the excitation of interacting resonances. The effect of pump synchronisation has been described more extensively in van Rijswick (2007). The effect of pump synchronisation is shown in Figure 8 in which pressure pulsation simulation results of are shown of a large pump station with and without pump synchronisation. In Figure 8 one can see a reduction of the pressure pulsation level larger than a factor 10 by the use of pump synchronisation. This extreme reduction is the result of the very high amplification of the flow pulsation by the resonance modes as their dampening is very small. This is also a result of the law of scale as the inertia to dampening ratio increases for increased system size.

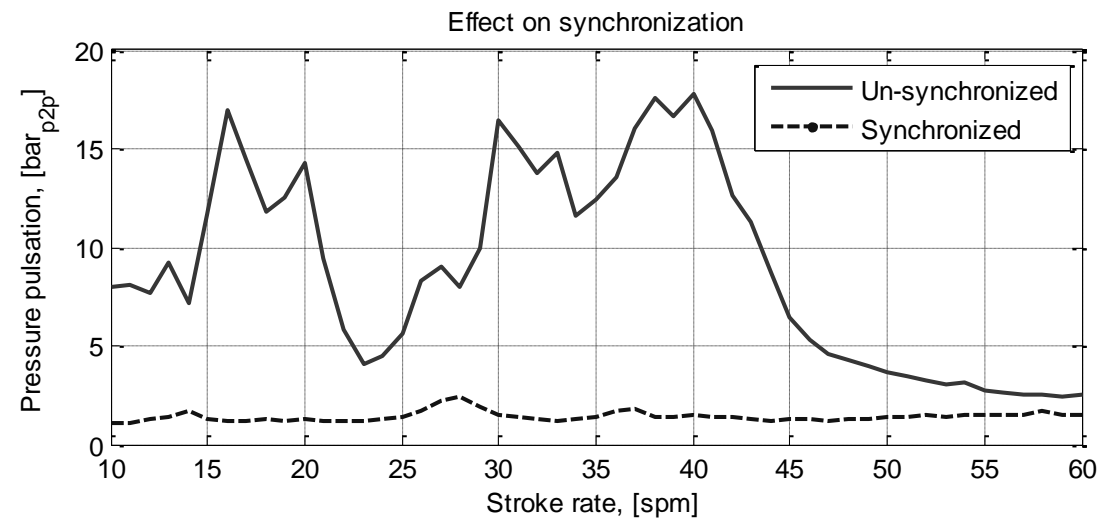

Figure 8 Simulation of the effect of pump synchronisation on pressure pulsations

\section{Conclusions}

This paper described the developments which enabled the design of GEHO piston diaphragm pumps for high capacity applications:

- Development of GLORES, a load balancing system for single acting piston diaphragm pumps which significantly increases the power rating of triplex single acting power ends.

- Power end component design for bi-directional loading in GLORES equipped triplex single acting piston diaphragm pumps is based on proven technology of double acting pumps, while maintaining the benefits of the liquid end of triplex single acting piston diaphragm pumps.

- The increased power rating by GLORES allows the selection of a smaller number of pumps in high volume pump stations which minimises capital as well as operational costs while maintaining a high reliability.

- As GLORES increases the power rating of a pump, much higher flow rates per pump are possible which poses several specific challenges on the pump liquid end from a dynamic perspective. Based on experimentally verified numerical models the following developments enabled a reliable pump design from a hydraulic perspective:

- optimum valve design for balancing wear and valve dynamics

- improved pulsation dampener layout in order to limit high frequency pressure pulsations

- pump synchronisation in order to exclude the excitation of interaction resonances in multi pump installations with dramatic decrease of pump station pressure pulsation level

○ development of the world largest pump diaphragm.

These developments enable the use of piston diaphragm pumps in high volume application such as large red mud or copper tailings systems, large concentrate pipelines or larger flow digester feed applications. 


\section{References}

ANSI/HI standard 6.1-6.5-1994 (1994) Reciprocating Power Pumps, Hydraulic Institute, USA.

Gandhi, R., Weston, M., Talavera, M., Brittes, G.P. and Barbosa, E. (2008) Design and Operation of the World's First Long Distance Bauxite Slurry Pipeline, Light Metals 2008, Vol. 1, Aluminum and Bauxite, D.H. De Young (ed), The Minerals, Metals \& Materials Society, March 2008, pp. 95-100.

Gandhi, R.L., Snoek, P.E. and Carney, J.C. (1980) An evaluation of slurry pumps, in Proceedings 5th International Technical Conference on Slurry Transportation, Lake Tahoe, Nevada, USA, March 26-28, Lake Tahoe, Nevada, pp. 267-275.

Holthuis, C.H. and Simons, P.W.H. (1980) The GEHO diaphragm pump, A new generation of high-pressure slurry pumps, Hydrotransport 7, Sendai, Japan, BHRA Fluid Engineering and Slurry Transport Society of Japan, November 4-6, pp. 17-32.

Holthuis, C.H. and Simons, P.W.H. (1981) The economics of positive displacement slurry pumps, in Proceedings 6th International Technical Conference on Slurry Transportation, Las Vegas, Nevada, USA, pp. 156-161.

ISO standard, ISO 281:2007 (2007) Rolling Bearings - Dynamic load ratings and rating life.

Kuenen, J. (2008) Pumping and Storage of Bauxite Processing and Power Generation Residues, Xth Congress of International Committee for Study of Bauxite, Alumina \& Aluminium (ICSOBA-2008), Bhubaneswar, India, 28-30 November, pp. 242-253.

Lush, S.M. and Pope, P.B. (1987) The New Sealand Steel ironsand slurry pipeline, in Proceedings 12th International Technical Conference on Slurry Technology, March 31 - April 3, New Orleans, Louisiana, USA, Coal and Slurry Technology Association, Washington DC.

Rayo, J., Fuentes, R. and Orellana, R. (2009) Large tailing Disposal - Conventional versus Paste, in Proceedings 12th International Seminar on Paste and Thickened Tailings (Paste09), R.J. Jewell, A.B. Fourie, S. Barrera, J. Wiertz (eds), 21-24 April 2009, Viña Del Mar, Chile, Gecamin Limited, Santiago, Australian Centre for Geomechanics, Perth, pp. 271-278.

Simons, P.W.H. (1987) Große Membranpumpen für abrasive Slurries, Pumpen, 1. Ausgabe, Vulkan Verlag, Essen.

Stephan, F. and Navrade, D.H. (1984) Experiences during the commissioning of the iron concentrate pipeline at O.E.M.K/USSR, in Proceedings 9th International Technical Conference on Slurry Transportation, Lake Tahoe, Nevada, USA, Slurry Technology Association, pp. 175-184.

van Rijswick, G. (1991) Förderung von Slurries mit Hilfe von Membranpumpen, Pumpen, 2. Ausgabe, Vulkan Verlag, Essen.

van Rijswick, R. (2007) Pressure pulsation analysis of crankshaft driven positive displacement pumps, Hydrotransport 16, Cape Town, South Africa, 7-11 May, The Southern African Institute of Mining and Metallurgy and the BHR Group, pp. 219-230.

Venton, P.B. and Cowper, N.T. (1986) The New Zealand Steel ironsand slurry pipeline, Hydrotansport 10, Innsbruck Austria, BHRA, The Fluid Engineering Centre, Bedford, UK, pp. 237-246. 